SHS Web of Conferences 6, 03001 (2014)

DOI: $10.1051 /$ shsconf / 20140603001

(C) Owned by the authors, published by EDP Sciences, 2014

\title{
Analyze the Problems and Countermeasures on China's Food Safety Supervision in 2012
}

\author{
You Guangfu, GongTing \\ College of Public Administration, Central China Normal University, 430079 Wuhan Hubei, China
}

\begin{abstract}
Food safety is directly related to the public's health and life safety as well as the improvment of life quality. From a practical point of view, despite the unremitting efforts made by Chinese government to put in place and improve the food monitoring system, the food safety incidents keep cropping up. Under the context of the deteriorating contradiction between the increasing demand and short supply for food safety on the part of the general public and governments respectively, how to address the current problems of food safety monitoring system remains an urgent point. This thesis aims to make a statistical analysis with nearly one-year occurring incidents of food safety so as to expound upon various problems in food safety monitoring system. This article presents the viewpoints have building a major ministering system in structure innovation; forming an efficient multi-centered coordinated supervision mechanism in mechanism innovation and bolstering food safety in security innovation. Based on the countermeasures, attempts to work out and establish a practical and long-term mechanism to improve food safety monitoring system.
\end{abstract}

Keywords. food safety supervision; system defects; institutional innovation

\section{Introduction}

In recent years, the Chinese government has been improved in the legislation and regulation about food safety issues. Currently a legal system with Food Safety Law as a guide and some auxiliary laws such as Food Hygiene Law, Administrative Punishment Law on Food Hygiene, Agricultural Product Quality Safety Law, Consumer Protection Law, Communicable Disease Prevention Law and Criminal law has formed. The State Council and relevant departments has formulated and carried out series of food regulation which involved in production and processing of food safety, circulating, food service license, food logo, risk detection of food safety, food safety supervision and so on. It has formed an overall framework of laws about food safety and intensified punishment during the enforcement of law. In spite of repeated bans, food safety problems still exist as results of the unsound laws, the inaccurate standards and the lagging technology of food monitoring. Food quality and safety has caused widespread concerns in Chinese society day by day so that people thrown worries and questions on the problems about milk products and alcohols. On the basis of analysis of the incidents happened nearly a year before November, 2012, the author will investigate the long-term mechanism of improving food safety supervision.

\section{Statistical analysis of China's food safety incidents in 2012}

This is an Open Access article distributed under the terms of the Creative Commons Attribution License 2.0, which permits unrestricted use, distribution, and reproduction in any medium, provided the original work is properly cited. 


\subsection{Statistical methods and sample selection}

This article selects 20 food safety incidents for statistical analysis, which has aroused wide concern on society from January to November in 2012(table 1), the selected samples are mainly from various food safety news exposed by network media. Through the collation and summary of the online data, I get the classification of food safety events (figure1), the places where food safety events happened (figure2), and the rate of the national "Top Three" in the news' exposure (figure3).

Table 1. A little table of China food safety events in 2012

\begin{tabular}{|c|c|c|c|}
\hline Food safety incidents & Time & Location & Outbreak sources \\
\hline Alcoholic liquor excessive plasticizer & $\begin{array}{c}\text { November } \\
19,2012\end{array}$ & Multi-regional & Plasticizing agent \\
\hline Artificial eggs & $\begin{array}{c}\text { November } \\
4,2012\end{array}$ & Multi-regional & Resins, chemicals, food additives \\
\hline Hershey's chocolate maggots & $\begin{array}{l}\text { October } \\
18,2012\end{array}$ & Shandong & Maggots \\
\hline $\begin{array}{l}\text { Blue particles floating in the bright } \\
\text { milk }\end{array}$ & $\begin{array}{l}\text { October } \\
19,2012\end{array}$ & Shanghai & Milk floats \\
\hline Borax five benefit flour & $\begin{array}{l}\text { September } \\
20,2012\end{array}$ & Hebei & Carcinogenic borax \\
\hline $\begin{array}{c}\text { Township of the vegetables in cloud } \\
\text { pesticide residues }\end{array}$ & $\begin{array}{l}\text { September } \\
8,2012\end{array}$ & Shandong & $\begin{array}{l}\text { Excessive use of chemical } \\
\text { fertilizers, pesticides, hormones }\end{array}$ \\
\hline $\begin{array}{c}\text { Instant noodles paper barrel safety } \\
\text { controversy }\end{array}$ & August 9, 2012 & Multi-regional & The fluorescence exceeded \\
\hline Panyu "poison chicken wings" & $\begin{array}{l}\text { August 14, } \\
2012\end{array}$ & Guangdong & Gum \\
\hline $\begin{array}{c}\text { The robust water "pseudomonas } \\
\text { aeruginosa" }\end{array}$ & July 9, 2012 & Shanghai & $\begin{array}{c}\text { "Pseudomonas aeruginosa" } \\
\text { excessive }\end{array}$ \\
\hline Nanshan milk powder carcinogenic & July 22, 2012 & Guangdong & Strong carcinogen aflatoxin M1 \\
\hline Industrial salt, soy sauce & June 12,2012 & Guangdong & Industrial salt \\
\hline $\begin{array}{l}\text { Sheep milk powder "has much love" } \\
\text { killing bacteria }\end{array}$ & June 24, 2012 & Guangdong & Enterobacter sakazakii exceeded \\
\hline $\begin{array}{c}\text { The banned "braise in soy sauce meat } \\
\text { additives" }\end{array}$ & May 1,2012 & Nanjing & $\begin{array}{c}\text { Food additives "meat treasure } \\
\text { Kings" }\end{array}$ \\
\hline $\begin{array}{c}\text { Health care products "excessive } \\
\text { chrome" }\end{array}$ & May 26, 2012 & Multi-regional & Chrome overweight \\
\hline Hangzhou poison preserves & April 24, 2012 & Zhejiang & Food additives \\
\hline Swill-cooked dirty oil & $\begin{array}{l}\text { early April } \\
2012\end{array}$ & Zhejiang & Bad animal innards \\
\hline Lipton tea party & $\begin{array}{l}\text { early March } \\
2012\end{array}$ & Beijing & 17 kinds of pesticide residue \\
\hline Dead pork sausage & $\begin{array}{l}\text { March 27, } \\
2012\end{array}$ & Fujian & Dead pork \\
\hline Injecting shrimp & $\begin{array}{l}\text { February 16, } \\
2012\end{array}$ & Tianjin & Glue \\
\hline $\begin{array}{l}\text { Black workshop lime wash the melon } \\
\text { seeds }\end{array}$ & $\begin{array}{l}\text { January 16, } \\
2012\end{array}$ & Shanxi & Lime \\
\hline
\end{tabular}




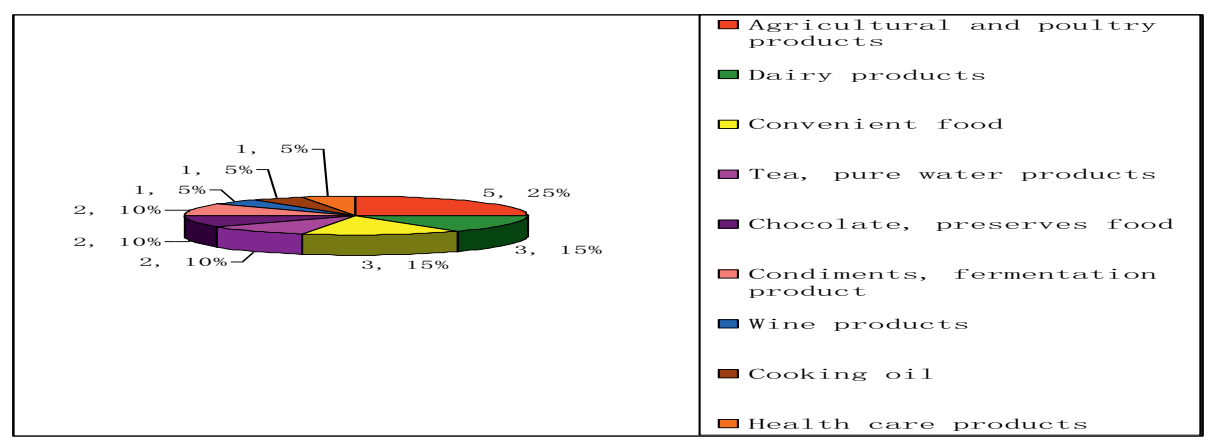

Figure 1. Food safety events classification scale drawing in2012

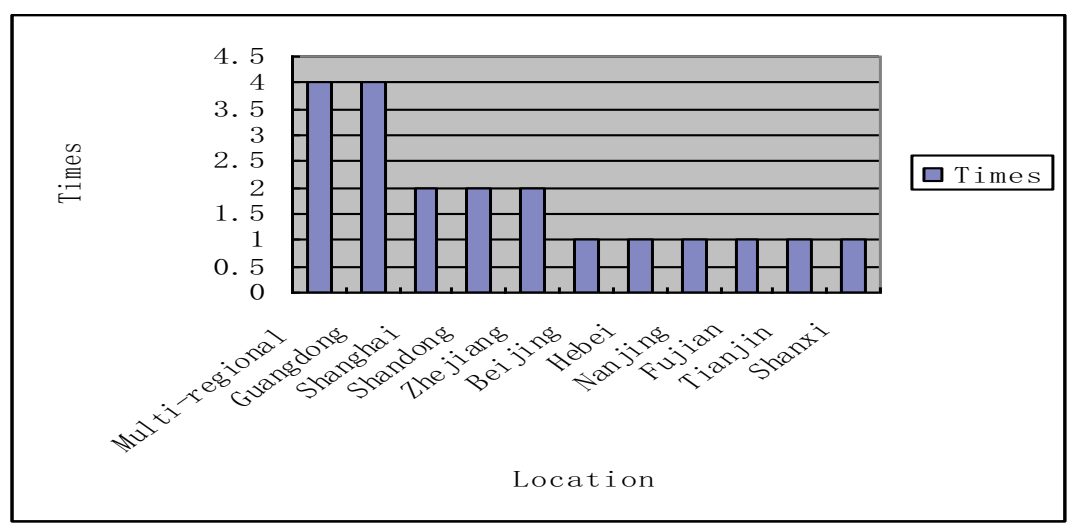

Figure 2. Food safety events location map in 2012

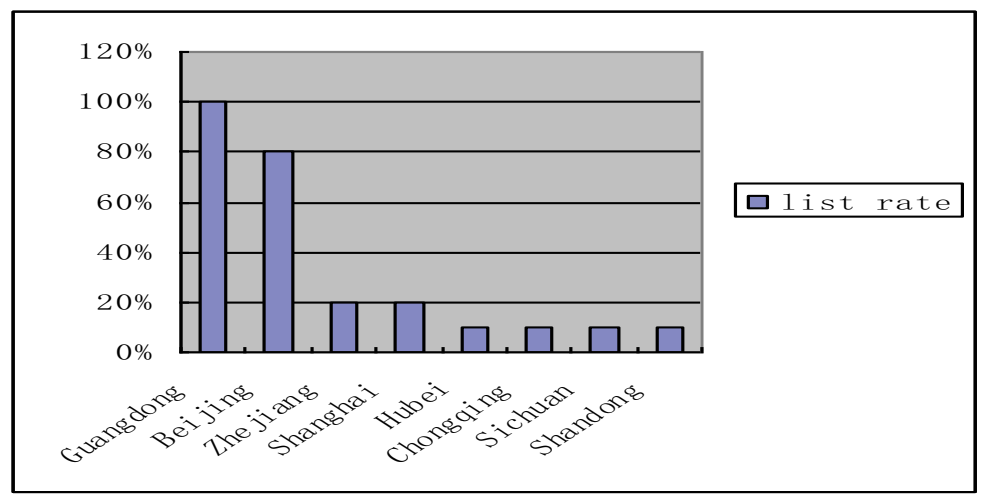

Figure 3. The "top three" list rate for the number of news exposure（from http://www.zccw.info/report/2）

\subsection{Results and analysis}

From the above chart we can see, Chinese food safety events involved a wide range of areas and the exposure has increased year by year. The problems of poultry farming and milk products highlight, especially in food additives, substandard food hygiene quality; microbial contamination in the food, pesticide and veterinary medicine are still at a certain level of residual; hidden troubles exist in food processing and transportation, even in some new food. Whether in the primary agricultural markets where illegal use of pesticides and abuse plant hormones exist or in the field of food processing and circulation where illegal use of additives and counterfeit products occurs continually, the problematic 
food is not strange in our daily life as they frequently be witnessed so that people nearly reach an extent of "turn pale at the mention of food".

As can be seen from the results presented in the incidents of China's food safety in 2012, there are several problems in China's food safety regulatory system as following:

(1) Bull management exist in government departments, social collaborative governance is week. In sub-regulation mechanism, each department is responsible only for their own areas of administration. As a result, food safety regulatory failure occurs. The responsibilities among various departments are unclear and cross and there is no mechanism to strengthen collaboration. The consequence must be the low efficiency of supervision, just like the phenomenon of "eight departments fail to manage a pig". After the occurrence of food safety events, under the strong pressure from media and public opinion, though government departments took special actions to investigate the events, most of the actions ended up with nothing definite. Instead of immediate investigation and clarification, regulatory departments choose to shirk and evade from their responsibilities, or even be silent. Kinds of food safety events caused a great impact in the society. The government's dereliction in the food safety supervision aroused criticism and skepticism among the public and media. The ineffective supervision reflected the drawbacks of the food safety regulatory system. Meanwhile, because of lacking of an effective way to participate in the supervision, social actors' participation is not strong, such as non-governmental organizations, enterprises, consumers and so on.

(2) The area of food safety supervision is limited. The regulatory legalization and technology have fallen behind. On one hand, there are so many related laws, rules and various standards going with Food Safety Law, as Food Hygiene Law and Agricultural Product Quality Safety Law. The Law-group status appears in the field of food safety supervision, laws and regulations are too much but nonsystematic and blind areas still exist in normative area. On the other hand, with the development of modern food industry and manufacturing technology, many artificial materials and new food enter into publics' view. The new food is not yet included in the Chinese government's supervision of food safety. In terms of the new food, there is no uniform regulation for risk monitoring and evaluation, production license, regulatory departments and safety standards. This reflects the blind area of the standards of Chinese food safety supervision. Meanwhile, our existing food-inspection technology is not high. There are several problems, such as lack of advanced inspection technology, backward equipments, lack of talents of inspection technology and so on. There is still an obvious gap between developed countries and us.

\section{Measures to improve food safety regulatory system}

In the author's view, to improve food safety regulatory system, three innovations should be carried out:

\subsection{Institutional innovation, establish large departments of food safety regulation}

In China, multiple departments work together on food safety regulation. Segmented regulation is adopted at present. With the unified leadership by the Food Safety Commission, the affiliated food safety department makes comprehensive coordination of Department of Agriculture, Quality Inspection, Industry and Commerce, as well as Food and Drug Supervision. On the surface, it looks like that different departments in charge of different aspects of the food chain. Actually, the departments are always selfish, profit-driven and they also tend to shirk their responsibilities. This is becoming really hidden dangers in segmented regulation. The one-to-one responsible mode failed to solve the problem of overlap, absence and offside in the management. This is not only costly but also inefficient.

For the above problems, it is necessary to make institutional innovation. We should establish large departments of food safety regulation to improve the administrative system. In the first half of 2011, after the clarifying of ten aspects involved in multi-link and inter-departmental supervision made by Shanghai government, Shanghai Food Safety Commission and Food Safety Office organized 
the relevant departments to make repeated researches, communication and coordination in the matter of food-peddlers, instant make and sell, bean sprouts, pre-packaged box-lunch and other new food patterns. They made clear measures one by one for regulatory body, corresponding requirements and security of market supply. The system has been basically formed with the two-levels' government, three-levels' management and four-levels' network, as well as compartmentalized structure and comprehensive supervision. Therefore, we can learn from Shanghai Government's approach and set out to establish large departments of food safety supervision: (1) Combine the departments related to production and circulation, such as State Food and Drug Administration, Department of Agriculture, State Administration of Industry and Commerce and State Administration of Quality Supervision, Inspection and Quarantine. On this basis, we can establish a large Market Supervisory Authority together with lower levels' counterparts in every region and county. At the same time, cooperation between Ministry of Health and Public security bureau should be taken out to investigate the food safety events and solve them. We can strengthen the cooperation and build the punishment system and the platform for information disclosure and communication. Ministry of Public Security should carry out punishment of the enterprises involved in food safety events. (2) Separate decision-making and execution in the whole system of government supervision of food safety. In addition, enterprises, consumers, non- government public departments and social forces should be considered as environmental variables of government supervision of food safety. Successful government supervision lies in seeking out consistency and coincidence between environmental variables and government supervision.

\subsection{Mechanism innovation, establish an effective mechanism of multi-center collaborative regulation.}

(1) For modern food safety regulation, we can establish traceable system of food information which is important measure to accomplish the entire management from the farm to our dining table. Beijing Dong Shang Fang Yuan Farming Development Co. reached the relevant requirements of the EU traceability standards after they use the product quality tracing coding, therefore to avoid the exporting-failure caused by lack of trade measures. So we can establish food information traceable system on the following aspects: a) In the field of edible agricultural products, establish biographical system of agricultural planting and cultivation as well as file information of the filed. It must be strictly controlled to use five highly-toxic and highly-residual pesticides, prohibited veterinary drugs and illegal feed additives. Animal-sourced food must be traceable. During the whole process of animals' birth, breast-feeding and fattening, it is necessary to record the information of cultivation, medication, epidemic prevention and the use and testing of feed. b) Implement strict supervision on food production and processing, especially on the key links as raw material controlling and inspection of finished products. Food Additives and market access must be strictly controlled. Make sure that each batch of food will be seriously inspected. c) Use monitoring and traceability system for food safety during transportation and logistics. Record the information of all the trucks' models, license plate number, the drivers' names and their health certificates. Applications include GPS, RFID and temperature transducers can be used to monitor the traveling tracks, the trucks' doors and the temperature of the food. All of these are to ensure food safety during the transportation. d) Set up regional databases by using the total information of the record of field operations, picking, transportation and food processing in the factories. Centralize all the data and send it to Department of Food Hygiene, then to the quality retrospective instruments in each supermarket. These data should be regularly updated and given to consumers as feedback. Enable consumers to query information of food safety and eat safe food. e) In terms of catering services, we can organize trainings for all the staffs before they go to work. Establish records of menus, raw materials and reserved samples. Establish HACCP system and carry it out strictly. Stick to the whole traceability of raw materials purchase, thoroughly cooking, standard tableware disinfection, "five special" about cold meats and harmless treatment of kitchen wastes.

(2) Implement prohibition of industry admittance. For food production enterprises whose catering 
service licenses were revoked because of illegal actions, industry prohibition within a certain period or a lifetime should be implemented for their important executives. Meanwhile, it should be filed by the public security department. Industry prohibition is not only safeguards for publics' interest, but also negative evaluation and disciplinary measures against illegal food enterprises. We should gradually widen the applicable scope of industry prohibition. For different offenses, set a reasonable prohibition of different levels and refine restrictions for specific person in charge.

(3) Set a food-recall system. Firstly, principles and conditions should be determined for food recall and the relevant sanctions regime should be improved. Secondly, management about recording basic information of production and operation should be implemented. Besides, we'd better implement management about tracking and identification of food information, as well as management about determination of responsibilities of the related business entities. Thirdly, adhere to the principle of combination of traceability and food-quality certification. Reduce repetitive work in enterprises, Reduce costs and promote the effective operation of the system.

(4) Improve risk assessment of food safety. Implement disclosure of food safety information. Determine the basic content and process of risk assessment. Accurately identify and assess the presence of potentially hazardous food during the process of hazard identification, hazard characterization and exposure assessment. Development of food safety policies and standards should be based on the results of risk assessment and should be uniformly implemented by Specialized Risk Assessment Committee. At the same time, strengthen globally collection and sharing of information, enhance the level of globalization of the food safety management. Scope, content and level of food safety information disclosure should be determined uniformly. The disclosure should include information of producers and traders, consumers, food safety scientists, researchers and government regulators.

(5) Focus on their credibility during the management of food enterprises. Considering the aspects of credit supervision, collection of credit information, credit evaluation, disclosure and punishment, we can establish a credit-evaluation system including the government, social sectors, and the third-party agencies. Set up the appropriate credit index, classification and results application.

\subsection{Support and protect innovation, set up powerful backing of food safety.}

(1) Develop and implement unified national standards for food safety. In terms of standard management, Food Safety Commission should integrate the existing security standards and build unified national standards; risk assessment is a prerequisite for the development of standards, we can promote the development of risk assessment to achieve the scientific standard; food safety standards should be codified, we need to highlight its authoritative position; Food Safety Commission should strengthen international cooperation in basic study and use international regulatory standards for reference, then actively participate in formulating international standards for food safety. We should take effort to keep pace with international standards.

(2) First of all, inspection of food safety regulation should be strictly carried out and accountable. Strictly comply with the sampling procedures, make sampling inspection of common food, start the regulation immediately when substandard products are recognized by law and, the existing relevant licenses must be strictly checked; next, modify and improve laws about government regulation of food safety, conduct overall assessment of food safety supervision. Everyone should be responsible for dereliction of duty. Supervise and restrict execution of government regulation. Thirdly, we can use public interest litigation to control activities which are harmful to food security interests of the public. Use the law in a more equitable way to resolve disputes in the field of food safety.

(3) Information should be disclosed timely and accurately. Network, newspaper, TV and mobile phone can be used to reveal information to the publics. For instance, there are special reports, exposure, warnings and so on. It is significant to build public confidence in food safety; encourage experts and others to open up science columns in media, reduce consumers' panic caused by reports of food safety incidents; popularize the knowledge of food safety and publicize the food safety awareness among enterprises, schools and communities. 


\section{References}

1. Food Safety Law of the People's Republic of China. China Legal Publishing. April 2009.

2. Supporting the provisions of the Food Safety Law of the People's Republic of China. China Legal Publishing. 2010.

3. Zhou Yingheng. Modern food safety management[M].China Economic Times Press. 2009.

4. ZhangTao.The reasearch on regulating of food safety laws[M]. Xiamen University Press. 2006

5. Liu Zhiyan. Response to the food security crisis - China's agricultural products quality and safety objectives and system research[M]. Qingdao Press. 2005.

6. Yan Haina, Nie Yonghao. Food safety regulatory mechanism of cooperation dilemma explore: the perspective of the relationship contract[M]. Chinese Public Administration. 2009(10).

7. Chen Junshi.The status of foreign food safety Enlightenment to China[J]. Health Law in China. 2002(10).

8. WangHu,Li Changjian. Reflection and reorganization of the the mainstream paradigm crisis: China's food safety governance model[J]. South China Agricultural University Newspaper. 2008(4).

9. ZhangLei. 2006-2007 Shanghai commercially available food contaminant monitoring results[J]. Environmental and Occupational Medicine. 2008(4). 